\title{
Everything Not Saved Will Be Lost: Preservation in the Age of Shared Print and Withdrawal Projects
}

\section{Zachary Maiorana, lan Bogus, Mary Miller, Jacob Nadal, Katie Risseeuw, and Jennifer Hain Teper}

\begin{abstract}
This paper's review of current issues in shared print retention and preservation identifies such shared issues as the cataloging and validation, retention and withdrawal of holdings, loss rates, current condition of holdings, recommendations for the number of copies to retain, and storage environments. Library institutions require a communitywide dialogue assessing practical retention concerns. We hope that our recommendations and discussion will serve as a call to action for further study and greater interest in strong cooperation at both institutional and repository levels, including collaborative action for multiple levels of collection assessments.
\end{abstract}

\section{Introduction}

Large-scale collaboration has been central to academic and research library preservation since the 1980s. Working in concert to microfilm brittle books and serials, librarians developed prescient collaborative strategies to distribute the microfilm across the country to be shared between institutions through interlibrary loan. Since then, libraries' collection sharing networks have matured and diversified so that today's library collectives now share their collections and collection development strategies in a more structured and integrated manner. The development of shared print programs (SPPs) to provide expanded access has occurred in parallel with projects to reduce overall print holdings and shift usage to shared copies and digital surrogates. The progressive, synergistic effects of these trends in collections management are pushing library preservation programs to rethink how to preserve items beyond locally defined needs and goals, and toward building nationally focused strategies.

SPPs are a critical focus for large-scale preservation strategy, and further attention must be paid to the capabilities, logistical issues, scalability, and ideal policies associated with shared print retention. By shifting usage to a collective collection, SPPs developed with the primary goal of reducing the overall number of copies managed by a group of libraries, with an implicit

\footnotetext{
*Zachary Maiorana is at Library of Congress, email: zama@loc.gov; Ian Bogus is at ReCAP (Research Collections and Preservation Consortium), email: ibogus@princeton.edu; Mary Miller is at University of Minnesota, email: memiller@umn.edu; Jacob Nadal is at Library of Congress, email: jnad@loc.gov; Katie Risseeuw is at Northwestern University, email: k-risseeuw@northwestern.edu; Jennifer Hain Teper is at University of Illinois, email: jhain@ illinois.edu. (C2019 Zachary Maiorana, Ian Bogus, Mary Miller, Jacob Nadal, Katie Risseeuw, and Jennifer Hain Teper, Attribution-NonCommercial (http://creativecommons.org/licenses/by-nc/4.0/) CC BY-NC.
} 
assumption that access to these items will continue to be viable because there is a retention commitment. To date, libraries have committed to retain more than 40 million items in SPPs and to leverage those retention commitments to promote more extensive and reliable access to information for library users. ${ }^{1}$ Long-term preservation of shared print materials, however, has never been considered a leading priority.

In this paper, we examine what is necessary to leverage shared print infrastructure, combined with increased retention commitments, into an active system of preservation, intended here to mean a coordinated and sustainable program of work to mitigate against damage and decay, to engage in corrective treatments to keep materials usable, or to reformat materials when physical preservation is not practicable. Our proposed guidance is aspirational, but pragmatically intended to help libraries derive additional value from their existing retention commitments and investments in collections storage by treating them as primary and necessary steps toward more robust stewardship efforts.

Our paper calls for stronger cooperation among SPPs at large, thereby conferring the burden of retention to a larger network of committed parties and providing guidance about the criteria that make an SPP a reliable partner in explicit preservation efforts. Given the relatively recent inception of SPPs, ${ }^{2}$ efforts to establish concrete relationships between existent repositories are still nascent, the lack of which threatens the productivity of such massive retention efforts. Not all SPPs share scope and may leverage a variety of facilities, agreements, and capabilities, and not all facilities supporting SPPs are capable of taking thorough and effective preservation actions on behalf of their partners.

Included in our examination of a shift to active preservation-focused shared print retention is an appeal to the value of print retention as a corollary to the ongoing creation of digital surrogates of items originally published in print. We argue that the still-developing body of knowledge around the affordances of print and digital formats, involving research in cognition, tastes, and cultural preferences, as well as a variety of approaches to scholarship that are informed by both print and digital versions of a work, show specific benefits of print reading in several common use cases. Print preservation permits libraries to have greater accessibility and more diverse options for access, allowing support for patrons with limited access to digital resources and those with learning and cognitive disabilities. Recognizing that acquisition of born-digital resources and creation of digital facsimiles are vital functions in our evolving collections management practices, however, this paper argues that digitization is not antagonistic to the sustaining value of print and that there are compelling incentives for libraries to maintain strong positions in both formats.

Print preservation carries real costs, however, in investments in storage space, in staff devoted to handling materials, and in conservation efforts for printed materials. Aggregating print materials using SPPs creates an opportunity to make investments in collections care that are less diffuse and can achieve a better return in terms of libraries' collective ability to ensure that the uniquely held information and character of printed materials is kept intact. To safeguard long-term access to our rich print heritage, a plan for responsible, cooperative retention is the clearest path forward.

A key question surrounding the rapid recent development of SPPs is the purpose of their founding. As the Modern Language Association's “Concerted Thought, Collaborative Action" white paper-referenced in the below literature review -indicates, the programs are effectively "federating" collection management policy in libraries, a movement that permits more 
efficient policymaking. ${ }^{3}$ Expanding overall access and reducing local collection management costs are strategic victories for libraries, but obtaining those victories through a collective collection that lacks effective preservation mechanisms creates two critical strategic risks. The first is that the copy of first resort will be lost or damaged during the retention period or that the SPP will not successfully renew its agreements at the end of the retention period. The second is that works held only outside the SPP, copies of secondary or final resort, will become less available or fully unavailable. This may occur if multiple SPPs are acting in parallel without knowledge of one another's commitments or lending priorities, which may decrease the total supply of available print materials and the priorities for interlibrary lending of those materials.

To mitigate these risks, we argue that a far more logical approach is to organize for preservation administration as a cooperative movement among connected institutions to be included in SPP planning and allow preservation capabilities to underpin the SPPs' primary goal of reliable access. Without advantageous storage environments, inventory control measures, and access to adequate preservation services, SPPs cannot ensure ongoing usability of their shared materials. In turn, this diminishes the strategic value of a retention commitment. The benefits of including collection management as a core competency has led to an emerging trend among SPPs, with several large programs built on the foundation of libraries' investment in purposebuilt high-density storage facilities (HDS) that are designed for the long-term retention of library collection materials and aligns with a tradition of collaborative activity in preservation administration. HDS may also be operated as specifically designated institutions, through a memorandum of understanding (MOU) or legal incorporation, that prioritize collaborative preservation as a vital component of their mission and can sustain an effectively indefinite retention period. For these reasons, we argue that SPPs ought to include the preservation of print materials in service of their respective consortia as a key mission element.

This paper's review of current challenges in shared print retention and preservation identifies challenges in relation to such a mission change, including the necessary number of copies to retain, cataloging and validation, retention and withdrawal of holdings, loss rates, current condition of holdings, the adequate number of copies to keep, and storage environments. A discussion of these issues follows, functioning as a starting point for a communitywide dialogue assessing practical retention concerns. Our high-level recommendations serve as a call to action for further study and greater interest in strong cooperation at both institutional and repository levels.

\section{Literature Review}

These discussions about library collective activity take place in the context of libraries' reevaluation of their own service model in the early 21st century as attitudes toward the various roles print and digital formats are rapidly evolving. A review of relevant literature reveals a great deal of recent discussion of the role and significance of print, its relationship to the digital corpus, and the individual and collective responsibilities that libraries have in the management of print collections. Digital resources have replaced print resources for numerous library functions, especially in the area of ready reference materials and access to peer-reviewed, scholarly journal articles. Print has remained a core format of choice in several areas, though, favored for a variety of reasons that merit deep attention by professional librarians.

Print books support a variety of functions through their original artifactual form that argue for the need for preservation. They can act as a "leaf master" for a digital version, a concept advanced by conservator Gary Frost and put into practice by both JSTOR and the Internet 
Archive. ${ }^{4}$ Print books provide evidence of the history of printing and binding as trades and commercial enterprises, as artistic endeavors, and as access points to material culture. Publishing industry research further reports a sustained user interest in print books. ${ }^{5}$

Another issue bearing weight on the topic of print retention of monographs is the study of individuality in what are technically considered "identical books." ${ }^{\prime 6}$ In the final white paper from the Book Traces Project "Book Traces @ UVA," the authors state that their findings support the considerable risk of loss of unique identifying information-inscriptions, marginalia, and annotations known as "interventions" - that is not represented in the catalog and could be lost with deduplication efforts. ${ }^{7}$ In addition, with proper sampling methods, areas with an increased likelihood of interventions can be identified and targeted. ${ }^{8}$

Other authors provide a strong indicator that library collection management needs to focus on the means to cost-effectively accommodate multiple formats to provide for numerous access scenarios, rather than perpetuate a false dichotomy that sets up digital libraries as antagonistic to print libraries. Wolf investigates the way the brain accomplishes the task of reading, to explain how one media or another may be better suited to certain tasks or to the particular cognitive abilities of a reader. ${ }^{9}$ Wolf uses the concept of affordances to show how print and digital versions of a text may be seen as more or less perfectly optimized for a particular learning or research goal, or for the particular reading needs of differently abled users. ${ }^{10}$

Walsh examines the versatility of digital versus analog reading and writing in the research setting. ${ }^{11}$ Walsh's review of 206 articles argues that students' choices of paper and pencil or screen and keyboard was situation-dependent and not mutually exclusive, ${ }^{12}$ students showed different preferences for different purposes and in different situations. ${ }^{13}$ The cooperative advantage that is ready to be gained from providing both formats is the optimization of existing services. ${ }^{14}$ Research refutes that the future ought to hold the wholesale abandonment of one or another type of library service or collection. ${ }^{15}$

Research work in library science throughout the past decade explores the value of shared print retention and its possible approaches. Warning of the danger of abandoning print preservation programming simultaneous to the rise of electronic text, Kieft and Payne conceptualize a potential framework for collaborative management and preservation of print monographs. ${ }^{16}$ CRL has positioned itself as a leader in discussions of shared print management for serial holdings. The Center for Research Libraries interrogates challenges in physical print retention: that information available from current shared print initiatives falls short of the necessary level of detail to support sound risk assessments and decision-making; that information regarding the varying commitments of partners in SPPs is unavailable or vague; and that little data is available about the environmental conditions in which libraries store archived materials. ${ }^{17}$ Most recently, a similar call for action toward a more organized, national approach has come from the Modern Language Association, in which Cohen et al. argue for the creation of a cohesive system, including both governance and built structure, using both existing high-density book storage facilities and new purpose-built facilities to oversee the management of print collections. ${ }^{18}$

Work on SPPs exists in the larger context of the "collective collection," a term coined by Dempsey to describe a portfolio of research envisioning how libraries can shift from local provisioning of collections and services to increased reliance on cooperative infrastructure. ${ }^{19}$ The resulting report includes case studies of shared print projects, comparisons of print and digital corpora such as Google Books, investigation of copyright issues, and feasibility studies on different approaches to collective management of materials. ${ }^{20}$ 
The keystone of several seminal articles attempting to define title scarcity in relation to retention and preservation is Yano's 2013 piece, focusing on the results of a study completed several years earlier in support of research for Ithaka S+R. ${ }^{21}$ While the initial data analysis for this paper was conducted in 2008, the formal results were not published until much later. ${ }^{22}$ From the result, however, came two oft-referenced studies that, while different in purpose, use Yano's research to project longevity for access to titles, then use those projections to suggest better withdrawal practices or selection for preservation activities. ${ }^{23}$

Conway argues that libraries should consider retaining print masters to avoid loss as a result of error in digitization. ${ }^{24}$ Through this publication, Conway reports the results of a study of the image quality of a 1,000-item sample of 1.25 million volumes in the HathiTrust consisting of English-language books and serials published before 1923 that were scanned and processed by Google between 2004 and $2010 .{ }^{25}$ On a more philosophical vein, Silverman reviews the perceived pitfalls and errors in the 1980s and '90s newspaper microfilming projects and asserts that, without more careful planning, digitization could offer many similar mistakes and losses to print heritage. ${ }^{26}$

Regional and disciplinary approaches to collective print management have invigorated collaboration. Regions that share many high-volume collections can expect collaborative collection management to bring success to shared challenges, in much the same way that regional economic and infrastructure organization offer opportunities for utilitarian intermingling. ${ }^{27}$ Texas A\&M University and the University of Texas collaborated to develop the Resource in Common (RIC) model, in which both institutions chose to store deduplicated "low demand" print items in a shared high-density storage facility and maintain joint ownership of the items under the parameters set in an MOU. ${ }^{28}$ As the resulting Joint Library Facility (JLF) began to fill with volumes according to the RIC model, several medical collections underwent significant withdrawal, and JLF moved to retain the weeded volumes. ${ }^{29}$ The JLF project quickly became a regional node for the MedPrint network (a National Library of Medicine SPP) and a case in which libraries collaborated to fulfill a regional need employing the RIC model, while contributing to a national consortium. ${ }^{30}$

\section{Methods}

To generate data at the outset of this project, our research group proposed a survey to collect information on current attitudes and practices regarding retention, withdrawal, and other relevant issues. Before launching the survey, the research group consulted with IRB personnel who advised that, if a survey collects only factual information about institutional policiesrather than information such as opinions, attitudes, or beliefs - the research does not concern each "person" surveyed. Therefore, such a survey would not meet the federal definition of human subjects research that would require IRB review, nor would it require IRB exemption. As a result, our survey avoided such questions that would extend beyond the scope of institutional policy or practices. Subsequently, in 2015, we surveyed a variety of academic libraries (including members of the Association of Research Libraries [ARL], Oberlin Group Libraries, and others) to learn how institutions make decisions to withdraw or retain print monographs. We developed an online survey on current monographic withdrawal practices and policy development and distributed it to the ARL Directors and Oberlin Library directors email listservs as well as the Statewide California Electronic Library Consortium and American Library Association "New Director" listservs (see the survey protocol in appendix A). After 
the initial data collection period had passed, any libraries with known preservation programs (largely ARL member institutions) who had not responded were encouraged to respond through direct contact with their preservation administrators. Overall, we received 99 valid responses after deduplicating multiple responses from the same institution. Because listservs were used in our data collection method, it is impossible to precisely establish a response rate.

Following the completion of the withdrawal survey and the dissemination of our findings, our research group wanted to study preservation statements included in shared print agreements onto which libraries were signing. Much of the legwork in encouraging and guaranteeing stronger collaboration lies in such agreements; but, with no standards for policies across repositories, there is little extant information to advise institutions how to develop solid preservation measures. We conducted an environmental scan through an informal survey locating and reviewing MOUs or other administrative guidelines related to both centralized and distributed shared print retention agreements. The survey sought to tease out trends that support such factors including retention commitments, preservation commitments, storage environments, levels of validation, committed retention period, and ownership. It was decided to use only publicly available MOUs. The authors searched for written MOUs or codified policies that governed each of the 44 programs identified. Shared print programs were identified through the Center for Research Libraries' Print Archives and Preservation Registry (PAPR) ${ }^{31}$ and ARL's SPEC Survey $345,{ }^{32}$ as well as a few other known programs. A grid was then compiled to allow direct comparison of results.

\section{Findings}

A total of 99 institutions responded to the withdrawal survey. Four out of five (80\%) indicated that they had a withdrawal policy, but less than half $(47 \%)$ said that their policy was written down (32\% said their policy was not written, while $20 \%$ did not respond to this question). When asked how these policies were developed, 86 percent of responses indicated that policies were based on "discussions within the institution about local priorities and needs, comfort with risk, etc." The overwhelming selection of this response over other options (such as adapting language from other institutional policies, discussing policies with other institutions about cooperative or consortial priorities, or basing decisions on a study) suggests that policy development is still largely an internally focused process.

Policies most frequently covered withdrawal of duplicate print copies in the library and/ or withdrawal because of condition during preservation review. Responses stating that selections were targeted toward withdrawal of duplicate holding across consortia were lower than we expected, especially given the number of large, consortial SPPs in place or developing at the time. Since several of these policy scenarios were dependent upon the presence of electronic copies, the survey also asked respondents which repositories or content providers were included in their considerations. Responses showed that academic libraries rely most frequently on electronic copies in the HathiTrust or digital content owned or purchased by their own institution. (See appendix B for a more complete summary of the survey's results.)

Of 44 SPPs investigated during our MOU review, 13 had written MOUs available that were suitable for analysis. Such a rate of return indicates that 29.5 percent of SPPs researched at the time of our scan had publicly available MOUs published online. Appendix C shows our summarized statistical analysis. We found stronger preservation-related language in centralized SPPs, which use a single facility into which partner libraries deposit their books, than in the distributed models. Overall, these SPPs tended to be consortial or regional, with member 
libraries retaining ownership. In these arrangements with a centralized facility, the appropriate environmental conditions may be more strictly followed; not so in the distributed SPP model with much wider allowances for temperature and humidity fluctuations in individual libraries. Levels of validation, however, were found to vary widely across all models. While some SPPs require issue-level validation for serials and/or a physical review for completeness, some SPPs require only a simple collection analysis with no physical review of the item at the shelf - this poses potential risk for distributed SPPs, where the only authentication of an item being held is its presence in the library's ILS. The lack of essential preservation-focused language in MOUs runs counter to basic retention goals such as alleviating space constraints and creating efficient, systematic access practices. It is in the best interest of research institutions seeking to gain these benefits to develop policies in partnership with collaborating institutions.

\section{Issues Complicating a Commitment to Preserve}

The difficulty in outlining how to ensure the preservation of the printed record on a national scale begins with the data points that require further study. Keeping practicability in mind as well as identifying where we need more information is critical to success. To that end, developing proper withdrawal policies and MOUs requires an understanding of the issues in libraries that SPPs seek to engage and the barriers to creating mutually beneficial agreements.

In spite of their potential, the act of establishing large repositories with seemingly limitless scalability is difficult to render when considering the barriers to such expansion. How might each item be processed in such large collections? Would imposing strict preservation standards create less efficient systems than the source institutions provided before withdrawing the materials? This conversation warrants further discussion, with a specific eye toward creating cooperative withdrawal practices, MOUs, and procedures that share information regarding condition and other factors between collections managers. Most imperative to solving the challenges ahead is the generation of more research on relevant issues.

In addition to scalability and the print-versus-digital argument, numerous key issues require thorough discussion during the nascent stages of SPPs' existence. The administration of repositories themselves as well as the agreements that dictate withdrawal and retention practices ought to consider these issues as key influences on policy on individual and macro levels. With special consideration for preservation as a motivating factor for withdrawal and retention practices, the following sections discuss nine noteworthy issues and barriers relevant to our arguments: Record Quality and Accuracy; Cataloging and Validation; Recording and Sharing Retention and Condition Data; Decisions to Retain or Withdraw Holdings; Memoranda of Understanding in SPPs; Loss Rates; Current Condition of Materials; How Many Copies Should Be Kept; and Storage Environment.

\section{Record Quality and Accuracy}

Data-informed collection management must play a vital role in determining the appropriate level of investment in print, digital, and special collections. For libraries to make effective decisions about retaining and preserving content at a consortial or national scale, accurate records of library holdings are necessary. Inaccurate and incomplete bibliographic data themselves present a significant challenge to effective cross-institutional analysis of collections, and this challenge is compounded by a lack of certainty about the overall rate of accuracy for the collective metadata corpus. 
Cataloging discrepancies are ubiquitous among libraries, but some errors are more problematic than others in terms of collections analysis and comparison. For example, control numbers, including the OCLC number, LCCN, and ISBN, are essential for matching a library's holdings against WorldCat, HathiTrust, and other target datasets. While these numbers are relatively straightforward, accurate data analysis requires that a) these numbers are actually present; $b$ ) the numbers are formed correctly; c) prefixes are entered consistently; and d) the numbers are assigned to the correct work. While efficiency, batch processing, and scale are essential to collective library operations, these approaches also introduce the possibility of systematic errors. Even a small rate of errors can result in a sizable raw number of exceptions; for example, even a set of 1 million records that is 95 percent accurate includes 50,000 errors. Because decisions will be implemented at local and consortial levels based on these data, libraries preparing to participate in shared print initiatives must also prepare for updates of local holdings and improvements to bibliographic data. Additionally, any future efforts analyzing number of copies on a national level must incorporate risk of inaccurate holdings information into any planning considerations.

\section{Cataloging and Validation}

Libraries cannot be sure that an individual copy physically exists and is cataloged correctly without first validating its holdings. To do this, a staff member must go to the shelf, make sure the copy is there, and then verify the cataloging accuracy. Anecdotal evidence claims that validation identifies numerous problems with potentially contributed holdings and that staff discover such problems more reliably with more investigative validation measures. Few formal studies exist, however, in this area, but in one case we can point to hard data: As part of the planning process for onboarding institutions into the EAST SPP, members recently performed a large-scale condition and validation project. In it, they looked at about 240,000 books from 40 partner institutions. They found about 95 percent of books were present on the shelf as expected, meaning that 5 percent were missing. This 5 percent not-on-shelf rate is not insignificant, should validation for participation in an SPP include only analysis of an institution's ILS and not a shelf-check.

Decision support tools have the potential to significantly reduce the labor intensity (that is to say, cost) of decision-making for retention, weeding, transfer to storage, preservation, and transfer to special collections. These tools allow libraries to set criteria, such as usage level, dates of publication, languages, number of copies available worldwide, as well as comparison groups, such as peer institutions, HathiTrust Digital Library, and others, and then review and compare the resulting lists. While these types of tools have the potential to streamline and scale decision-making, their use so far has been limited to one-time, targeted projects rather than ongoing planning. The ability to build more data-informed management practices could encourage thorough validation in addition to efficient withdrawal planning.

Further, greater inclusion of condition information in the MARC 21 Field 538 "Action Note," used to record condition data, preservation actions, and commitments to retention, could augment records to include preservation needs as a criterion for withdrawal or retention. Providing a decision support tool that links the preservation information in an institution's ILS would prioritize condition tracking and further fulfill the mission of tools like GreenGlass to support long-term print preservation in SPPs. 


\section{Recording and Sharing Retention and Condition Data}

In addition to ensuring records accuracy, one of the challenges of collection management at a networked level, particularly with regard to withdrawal of print materials, is sharing and accessing relevant data about holdings, including physical condition, commitments to retain, and commitments to preserve holdings. The MARC 583 field is widely considered the most appropriate venue for recording and sharing such data. Some SPPs require that shared print retention commitments are recorded in the 583 field in the local catalog; but, in practice, the usefulness of the field has been limited by a lack of discoverable retention commitments. In spring of 2018, OCLC announced availability of a Shared Print Registration Service, which allows batch loading and is intended to streamline the process of registering shared print retention commitments. This is a significant step toward development of the data infrastructure that allows SPPs and individual institutions to make informed collection management decisions based on the number, location, and retention status of copies.

While efforts to expand and facilitate use of the MARC 583 field remain focused on shared print retention commitments, its use for recording condition and other relevant, copy-specific information appears limited. A successful model for sharing condition information is UVA's Book Traces project, referenced in the above literature review, an undertaking that developed enhanced metadata schema with a specialized vocabulary to describe unique evidentiary or artifactual value in holdings across libraries and archives. As a result of the project, UVA streamlined the process to identify and describe unique artifactual content, such as marginalia, to prevent loss and duplication.

\section{Decisions to Retain or Withdraw Holdings}

When respondents were asked to identify which factor(s) they considered when deciding whether to retain or withdraw a monographic title, the responses show that libraries use a wide variety of factors; in some instances, almost any factor may be of value. The most commonly used factors for consideration appear to be physical damage or embrittlement, provenance or other factors that render a copy unique, and input from collection development guidelines or staff.

When the survey asked respondents to consider what research or guideline development might be useful in the future as they withdraw print monographs from their collections, the majority replied that "commitment to preserve at another institution" is the most desired element not currently available to them that would influence decisions.

The survey highlighted several trends. Many libraries are operating without a guiding document that outlines when and how they withdraw monographs, and even those who have a policy frequently note that it is now out of date and in need of revision. In most cases, the development of such policies is an internal process that does not take into account external factors that may influence a decision to withdraw or retain a title, or the need for communication within and outside the institution. Policies often do not address consortial preservation considerations; the number of copies of a title available at the state, regional, or national level; or the condition of duplicate copies within the institution. And, more practically, many institutions have neither the necessary resources nor the infrastructure to implement such considerations on a practical level, even if they are included in a policy.

While the survey data indicate that many policies do not currently address shared or consortial print preservation, they also suggest strong interest in leveraging existing shared 
preservation infrastructure. Respondents further indicated significant reliance on the HathiTrust Digital Library in making withdrawal decisions.

\section{Memoranda of Understanding (MOUs) in SPPs}

For books in centralized or distributed SPPs, most MOUs contain policies about the retention commitment, though it can range from 10 years to indefinite. As libraries depend on their consortial peers' collections, local withdrawal becomes an easier option; this raises concerns regarding the number of copies of a specific title kept and who bears the responsibility to retain, as well as how those data are recorded. MOU language uses "commitment to retain" instead of "commitment to preserve," which, to the preservation community, mean different things. The latter infers an attention to the continued usability of the book, not just a promise for its presence on the shelf.

In evaluating the MOUs of 14 SPPs, the study hoped to find specific information about retention, withdrawal guidelines, and environmental requirements. Seven of the SPPs have some sort of retention agreement, though not all are formalized; of these, only one repository has a permanent retention policy (University of California Shared Print). More common in retention agreements was a 10-, 15-, or 25-year term retention (6 SPPs), with clauses to revisit the retention length.

Replacement, treatment, or validation guidelines are broadly preservation issues, especially surrounding "last copy" concerns. Half of the MOUs surveyed have guidelines for withdrawals or for damaged book treatments (seven institutions). MOUs with specific procedures for cataloging review or validation processes are low (two and three institutions, respectively). The few institutions that keep retention notes put them in local catalogs.

\section{Loss}

There are several ways that loss can occur. Books are at risk of theft, accidental loss, damage, and mutilation. The chance of any of these happening depends on type of storage and accessibility. Books are at higher risk when circulating, and at lower risk when in a nonbrowsable storage location. It is inevitable that some items in any particular library collection will be lost, but loss is mitigated when that library has recourse to additional sources of material, such as interlibrary loan or replacement. Loss of intellectual information happens when there is a loss of physical material. Pages can be torn, ripped out, or defaced. They can fall out of loose bindings. Books in open stacks that are misshelved can be as inaccessible as if they were missing unless a library does regular shelf-reading.

There is a nonnegligible chance that any book in a circulating collection will at some point be lost, damaged, or otherwise rendered unusable over a period of decades. In 1986, Kohl established a generally accepted loss rate of 0.15 to 0.5 percent of circulating collections per year. ${ }^{33}$ Anecdotally, even in today's more digital environment, this percentage holds reasonably true. At a major ARL institution that is home to one of the authors, an internal survey found that current loss rates due to patron loss or losses found as a result of limited inventory projects resulted in an average annual loss rate of 0.11 percent as measured from 1998 to 2017. However, these percentages do not include any loss due to excessive damage or other decisions to withdraw an item from the collection. Therefore, the chance of loss (inclusive of withdrawal due to condition or incompleteness) increases as the stability of the item, through natural degradation and use, decreases. 


\section{Current Condition of Materials}

The current condition of each copy may be the factor with the largest impact. A book in such poor condition that it cannot be used does not serve its intended purpose, whether that be for research or as a backup for another copy. Furthermore, the current condition is essentially the starting point for current and future reliability. While very little will improve the current condition of an item on a chemical level, and they will in fact continue to degrade, there are ways of slowing future chemical degradation such as depressed temperatures or deacidification. Furthermore, the artifactual characteristics of books continue to be of value to scholars, and readers show an ongoing preference for print reading for a variety of purposes. For these users, materials in good physical condition are essential.

Many libraries are withdrawing books because of poor condition. There is an inherent assumption that other copies are in better condition, but that assumption is not based on evidence. While it is impossible to know the condition of every book held within the United States, a well-designed study could allow libraries to make generalizations. Book condition may have several contributing factors such as size of holding library, geographic location, place of publication, and publication date. Trying to identify where the best quality copies are held is critical for success.

An often-overlooked issue is that, in all cases, books will age and change over time. Preserving an exact experience (for example, reading a 1950s science fiction novel in 2017) is not the same experience of reading that book 70 years ago, nor will it be the same experience if reading it in another 70 years. The book itself has changed since its publication, and it will continue to change even if stored in a good-quality environment. Understanding what needs to be preserved and why will help clarify strategies.

It is critical that libraries broadly understand the issues of current condition of items nationally and locally. It is not that the condition of each item should be known, but rather what one can expect to make well-informed decisions. Will the condition of an item in hand tell us something about the condition of other items? Are there regional or demographic differences that could be generalized to find viable copies? Will the current condition tell us how long we can expect to rely on that copy to remain viable for its intended purpose?

\section{How Many Copies Should Be Kept}

When talking about preserving titles in the context of shared print, the conversation inevitably comes around to number of copies. No one has claimed to have identified an ideal number of copies to hold nationally, but many institutions have settled on a number when making local retention decisions. While it would be unfair to say these numbers are arbitrary, they are not made through rigorous analysis of carefully generated data. Nadal and Peterson problematize the lack of certainty when discussing how a locally chosen number affects the actual risk of loss: "Although we might assume [the chance that two dozen libraries will withdraw or lose duplicate copies] to be quite low, we have no definitive data to affirm or negate this assumption." ${ }^{34}$ The problem is that generating a recommended number is difficult, because to do so responsibly requires balancing several factors such as level of validation, condition, risk of loss, and long-term environmental storage, few of which have available data.

The digital preservation community has settled around a minimum of three copies, though some programs, such as LOCKSS, ${ }^{35}$ use more copies based on their preservation methodology. Preservation strategies for digital and physical items differ significantly, making it impossible 
to extend the model for the number of copies needed for digital preservation to physical preservation. The ability to make easily verifiable identical copies of digital objects is a major factor in the determination of the minimum number of copies. Additionally, digital objects are easily checked for damage, loss, or alterations. When one copy is found with a fault during these periodic checks, it is replaced with a new identical copy, keeping an adequate number of copies in perpetuity. It is not as possible to assess physical copies for loss or damage on a regular basis using similar automation. Even if it were, replacing a lost or damaged item with an exact replacement is difficult at best. On the other hand, no two physical copies will be exact matches, and minor damage on a physical object may not be problematic if there is no loss of content. Suffice it to say, the numbers of copies needed to secure digital objects and physical objects are not correlated.

\section{Storage Environment}

The authors of this paper are working with Dr. Candace Yano to develop a model for book survival probability. The model is still under development, but it is already starting to show what factors, most notably that of storage environment, have the highest impact on book survival. Other factors play crucial roles, but the real threat to books published between 1850 and 1980 is inherent vice present in their constituent materials. Reducing other types of loss is helpful but only until the paper breaks down to an unusable stage, at which point the costs outweigh the benefits.

Storage environment, by far, has the largest impact on book survival in its capacity to accelerate or assuage decay. A good storage environment is one of the most efficient preservation tools a library has at its disposal. Books and paper are impacted by environmental conditions because of the materials' inherent chemical makeup. The organic elements in mechanical wood pulp paper, animal products such as leather and hide glue, or wood byproducts found in composite board are all susceptible to the hazards associated with uncontrolled temperature and relative humidity (RH). Paper containing lignin becomes acidic and brittle; leather covers dry out and deteriorate. Unstable environmental conditions can have damaging effects on materials, such as the expanding and contracting of paper fibers or adhesives. Maintaining appropriate temperature and relative humidity levels helps slow the degradation process. While different formats have ideal temperature/RH set points, the common goal for highdensity storage facilities is 50 degrees Fahrenheit and 35 percent $\mathrm{RH}$.

The relationships among temperature, humidity, and life expectancy of a library book is complicated. The general rule of thumb is that, for every 9 degree Fahrenheit drop in temperature, the life expectancy of an item will double. Similarly, halving the RH will also double the life expectancy. Essentially this means that storing a book at 50 degrees Fahrenheit and 35 percent RH, a common high-density storage environment, will make a book last 6.25 times as long as a book stored at 70 degrees/50 percent $\mathrm{RH}$. If a book has 20 years left in its useful life and is stored in an open stack at the latter environment, its useful life would be extended an additional 100 years if it were to be moved to a storage facility with the former environment.

The MOUs of only 4 of 14 surveyed SPPs address environmental storage conditions. Additionally, HVAC standards are generally vague. Given the importance of cool, dry, and stable storage environments, more consideration for ensuring such suitable conditions must be a priority in written agreements. 


\section{Conclusion}

Shared print is one of the most exciting developments happening in libraries right now. It leverages technology to expand libraries' goals of making the most amount of material available to the broadest swath of users in a reasonable and cost-effective way. Perhaps the most ambitious desired outcome of shared print is the potential of collaborative collecting that reduces costs while actually increasing the depth of collections. But the resulting danger is collection management decisions without a thorough understanding of the challenges we have outlined. Such uninformed progress may lead to the greatest challenge to collaborative collecting: Will researchers continue to have access to these shared collections, or will inadequate long-term planning cause massive loss rates? We believe this question will one day be used as the primary metric of success.

The variables are known, but we can only identify the values of those variables through study and research. To further complicate the problem, many of the variables influence each other, which is why precisely determining the number of copies needed is so challenging. Without actual data, it may be possible to hedge bets by using arbitrarily high-risk values, but that will most likely result in a retention number that is unacceptably high. Instead, it is necessary to do some research to fully understand what is necessary to ensure titles remain accessible for as long as possible.

Nine challenges to preservation commitments in a shared print environment are outlined here, comprising a research agenda to inform prudent policy in the age of shared print and large-scale withdrawal projects. Four of these challenges require large-scale, data-oriented research projects with carefully determined samples to shape our understanding of materials held as part of SPPs: record quality and accuracy, cataloging and validation, loss rates, and current condition. The resulting data will, in concert with further collaborative discussion, partially inform policy relating to recording retention commitments, coordinated withdrawal, shared print MOUs, and determining an adequate number of copies (the ninth challenge, storage environments, does not require research-only focused implementation). Following careful study, researchers must share the resulting data and lobby for the adoption of conclusory guidelines. Only with a proper understanding of the challenges before us can we realize SPPs' full potential and appropriately share the responsibility of collective stewardship. 


\section{APPENDIX A. Withdrawal Practices/Policies Survey Protocol DEMOGRAPHICS}

1. What institution are you responding for? (open short answer)

2. What position do you currently hold? (select one answer that best describes your position)
a. Preservation/Conservation
b. Collections Management/Development
c. Cataloging
d. Acquisitions
e. Other

3. What type of institution do you currently work in?
a. ARL member library
b. Oberlin Group member library
c. Neither of the above

4. What is the total collection size in your institution?
a. Under 1 million volumes
b. 1-3 million volumes
c. 3-5 million volumes
d. 5-8 million volumes
e. 8 or more million volumes

5. Does your institution have an established preservation program or administrator?
a. Yes
b. No

\section{POLICY}

1. Does your library/institution have a policy on when to withdraw volumes? (The term "policy" as used in this question refers to any formal or informal written guideline as well general unwritten practices.)

a. If no, that's the end of the survey

b. If yes, continues on with the survey

2. Is this a written policy?

a. If yes, please attach a pdf of the policy and skip to question 4

b. If no, continue to question 3

3. How is the policy known?

a. Informal written guidelines

b. Verbal explanations to those responsible for carrying it out

c. Historical practice

4. Does your institution have any guiding documents or policies (such as mission statement or strategic plan) that present preservation as a responsibility of your library/institution?
a. Yes
b. No

\section{WITHDRAWAL PRACTICES}

1. My institution's withdrawal policy covers the following:

a. Individual withdrawal during preservation review

b. Deduplication of physical copies 
c. Deduplication of both print and digital copies

d. Mass withdrawal

e. None of the above

f. Other

2. Who at your institution makes withdrawal decisions? (check all that apply)

a. Preservation professional/support staff

b. Conservation professional/support staff

c. Collection management/development librarian/support staff

d. Subject specialists/bibliographers/support staff

e. Other

3. If your policy includes deduplication of physical copies, which of the following apply?

a. We withdraw all identical copies, excluding those in special collections

b. We withdraw all copies beyond a certain number (please enter number

c. Other

4. Does your institution A) currently use any of the following in its decision to withdraw on an item level; B) currently use any of the following in its decision to deduplicate; C) currently use any of the following in its decision for mass withdrawal; D) would use the following in its withdrawal decisions if available; or E) would not use the following information in its withdrawal decisions even if available.

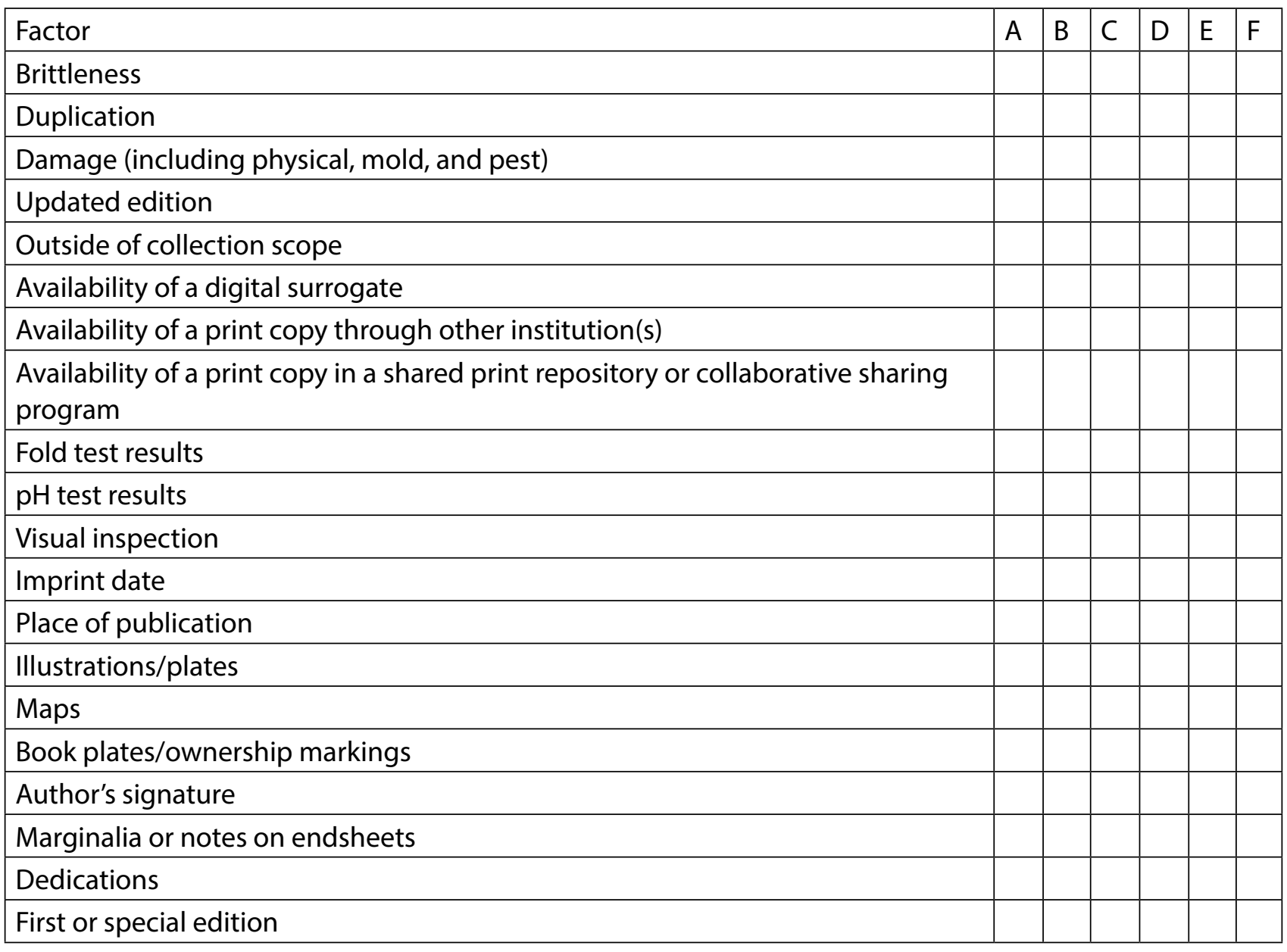




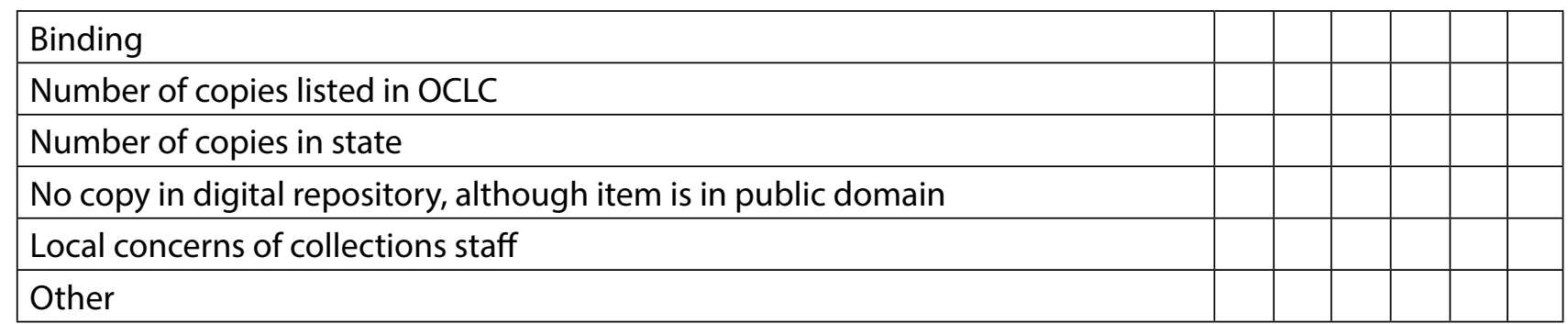

Please describe other criteria noted above.

5. What information is not currently in your institutional procedures, but would be incorporated if accessible?

a. Condition at another institution

b. Commitment to preserve at another institution

c. An easy test for your copy that could inform expected lifespan

d. Other (free text)

6. What is your withdrawal policy based on?

a. We borrowed our policy from another institution.

b. It is based on internal conversations where we determined by our institutional comfort level.

c. It is somewhat arbitrary.

d. It is based on a study (include name).

7. Would your institution be willing to send a volume it is withdrawing to another library?

a. Yes (we are currently doing this)

b. Yes (we would be willing to do this)

c. No

Comments:

Contact information, title, and if willing to be contacted. 
Everything Not Saved Will Be Lost 961

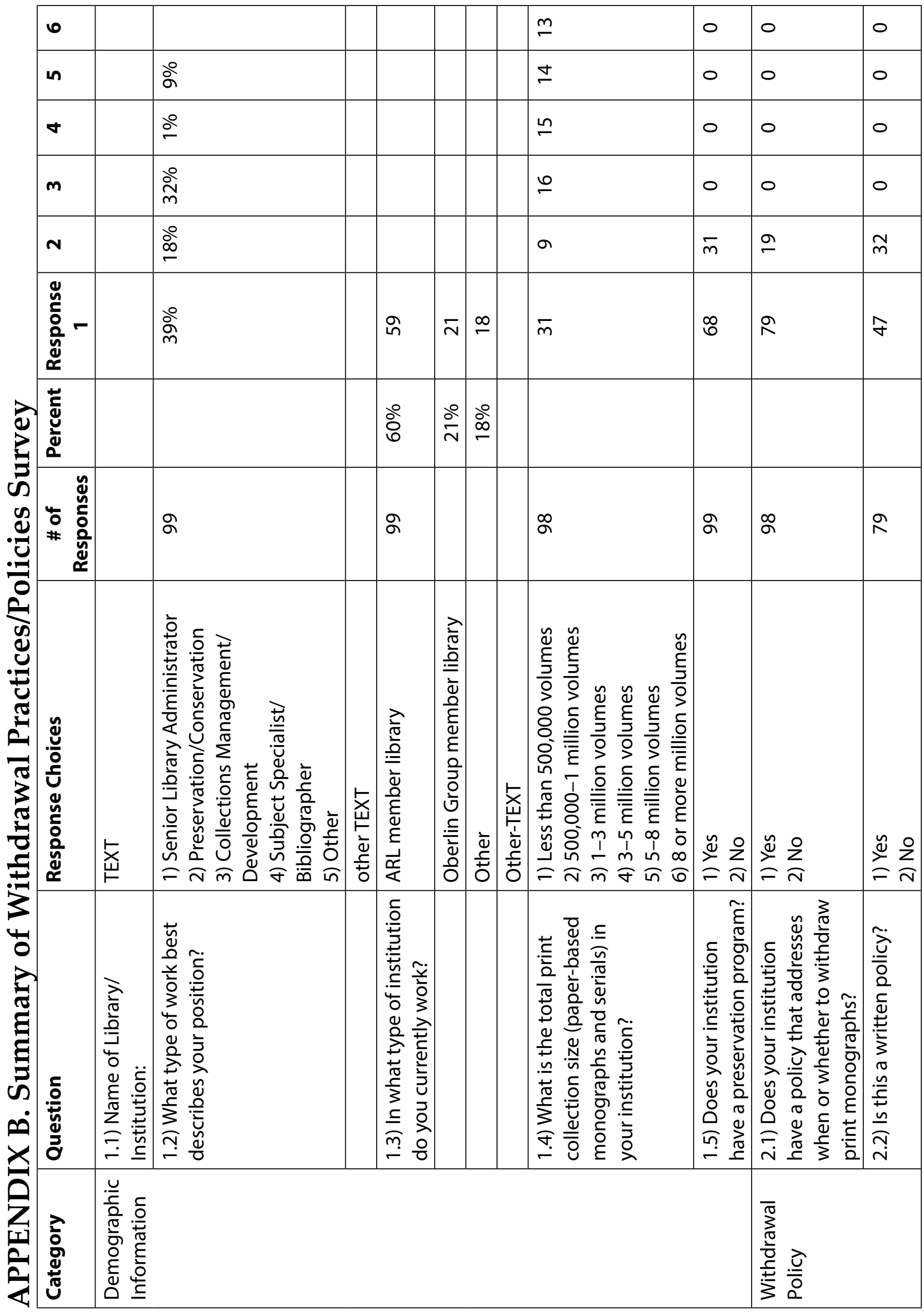




\begin{tabular}{|c|c|c|c|c|c|c|c|c|c|c|c|c|c|}
\hline$\bullet$ & & & & & & & & & & & & & \\
\hline in & & & & & & & & & & & & & \\
\hline $\boldsymbol{\sigma}$ & & & & & & & & & & & & & \\
\hline$m$ & & & & & & & & & & & & & \\
\hline $\mathbf{N}$ & & & & & & & & & & & & & \\
\hline 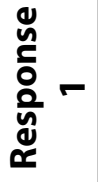 & & 우 & $\mp$ & ๖े & 우 & $\approx$ & & $\stackrel{m}{r}$ & ర & $\stackrel{\infty}{-}$ & $\stackrel{2 n}{\leftarrow}$ & Ln & \\
\hline 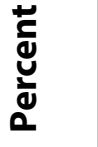 & & ڤ̊ํํ & $\stackrel{\text { 巳̊ }}{ \pm}$ & ठి̊ & $\stackrel{\text { ஸे }}{\mathrm{n}}$ & 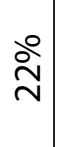 & & $\stackrel{\stackrel{2}{2}}{\stackrel{2}{2}}$ & \&ి & $\stackrel{\text { }}{\sim}$ & ઠ̊ & ठे & \\
\hline 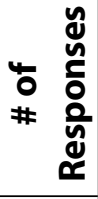 & & $\hat{\wedge}$ & & & & & & $\hat{\imath}$ & & & & & \\
\hline 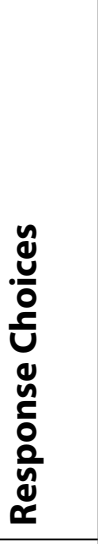 & & 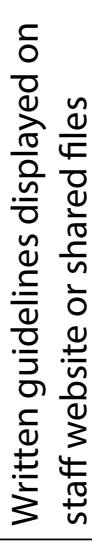 & 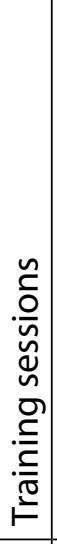 & 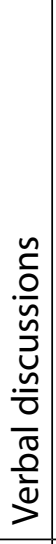 & 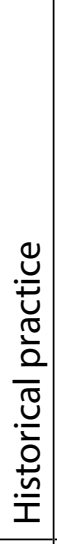 & 㐫. & 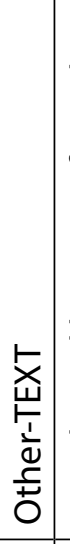 & 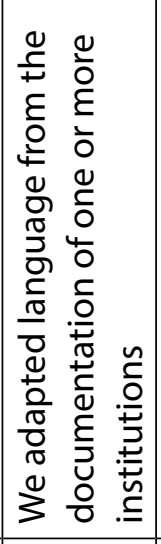 & 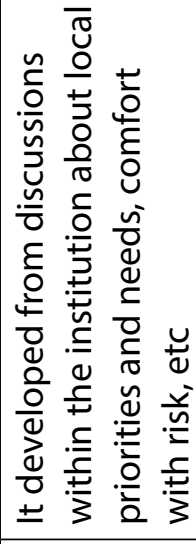 & 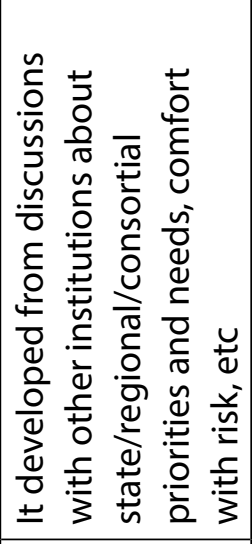 & 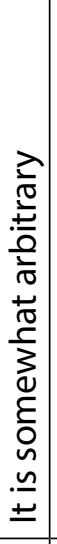 & 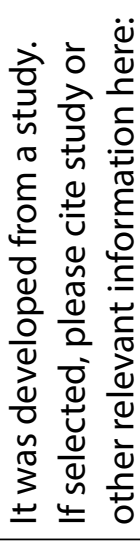 & : \\
\hline 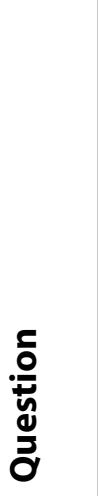 & 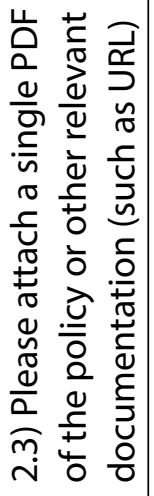 & 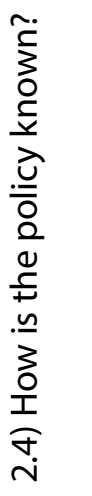 & & & & & & 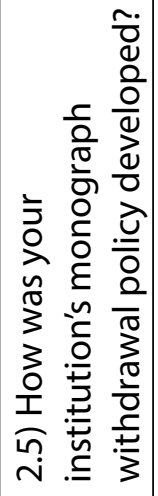 & & & & & \\
\hline 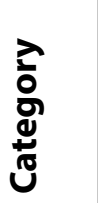 & 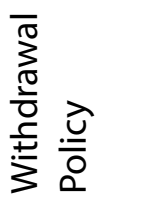 & & & & & & & & & & & & \\
\hline
\end{tabular}


Everything Not Saved Will Be Lost 963

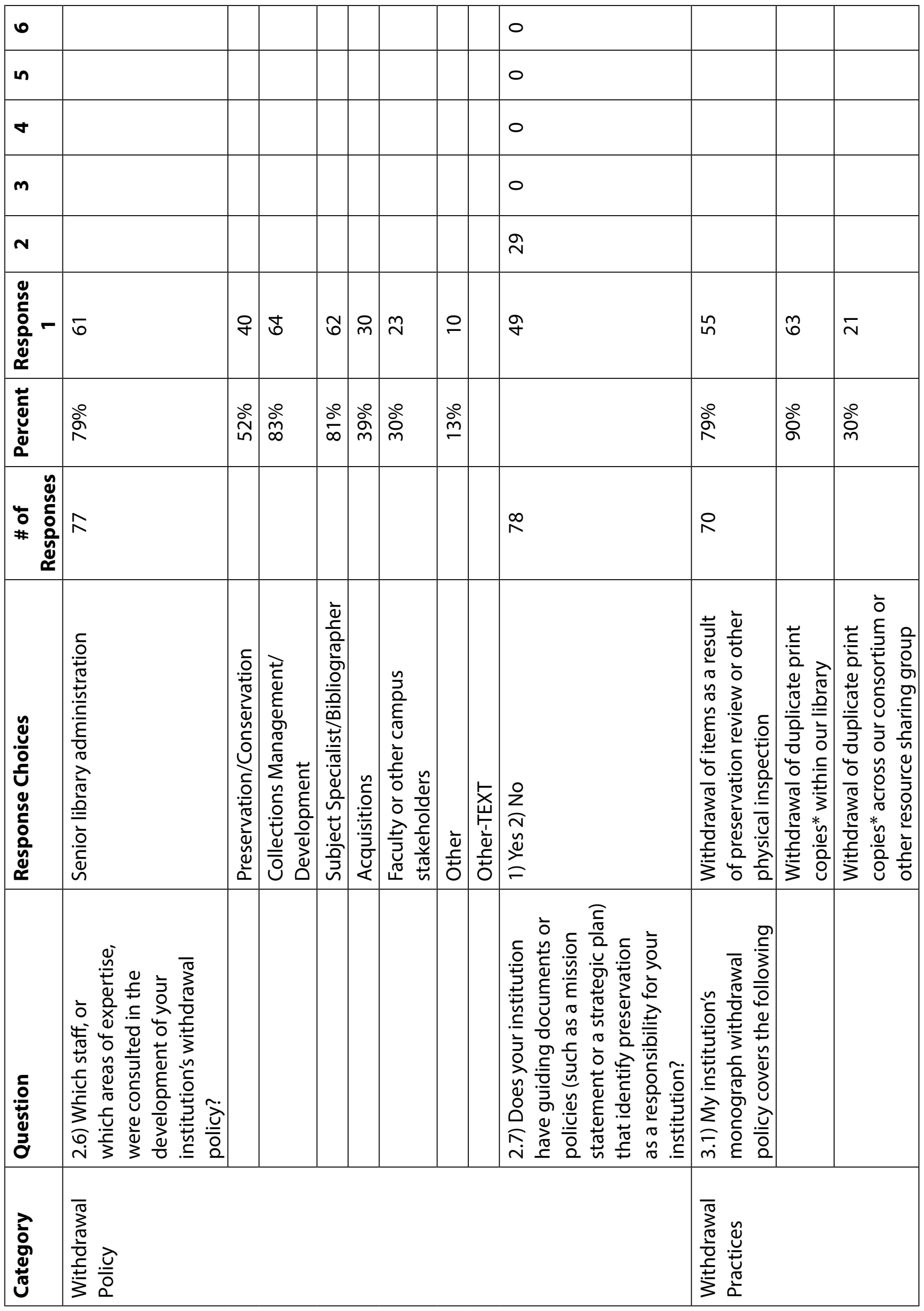




\begin{tabular}{|c|c|c|c|c|c|c|c|c|c|c|c|c|c|}
\hline \multicolumn{14}{|l|}{0} \\
\hline in & & & & & & & & & & & & & \\
\hline $\boldsymbol{\nabla}$ & & & & & & & & & & & & & \\
\hline$m$ & & & & & & & & & & & & & \\
\hline $\mathbf{N}$ & & & & & & & & & & & & & \\
\hline 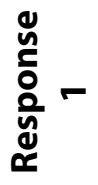 & $\stackrel{\infty}{\sim}$ & $\mp$ & - & $\approx$ & 0 & స & $\stackrel{\stackrel{n}{\sigma}}{\sigma}$ & $\stackrel{\infty}{m}$ & in & 8 & $\lambda$ & ฏิ & $a$ \\
\hline 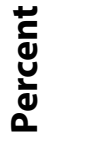 & ஓे & ठ̊ & $\stackrel{\circ}{\circ}$ & $\stackrel{\circ}{\stackrel{\sim}{\sim}}$ & ঃ̊ & $\frac{0^{0}}{m}$ & $\stackrel{\circ}{\stackrel{+}{0}}$ & $\begin{array}{l}\stackrel{0}{+} \\
\dot{+}\end{array}$ & 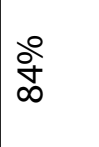 & ○े & ஓे| & $\frac{\partial^{\circ}}{\dot{\gamma}}$ & $\stackrel{\stackrel{\circ}{m}}{\square}$ \\
\hline 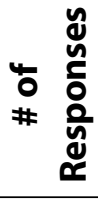 & & & & & & & 옹 & & & & & & \\
\hline 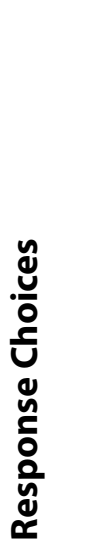 & 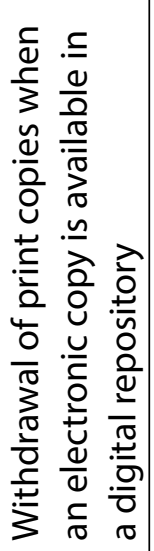 & 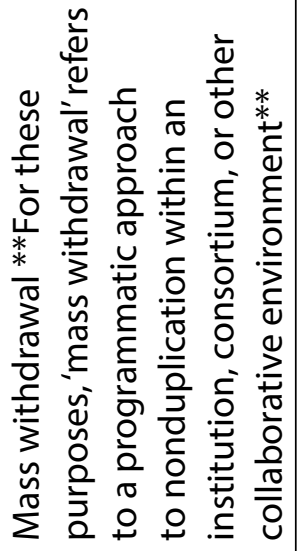 & 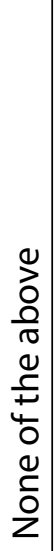 & $\frac{\bar{d}}{\frac{\Phi}{\Delta}}$ & 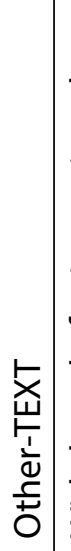 & 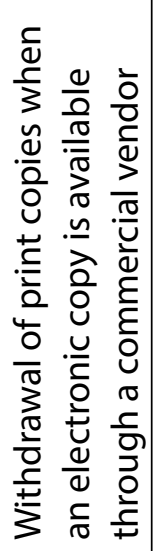 & 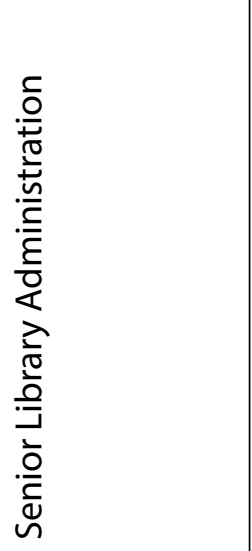 & 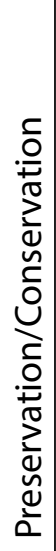 & 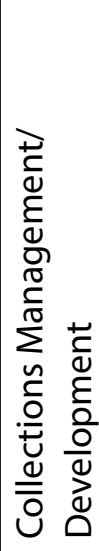 & 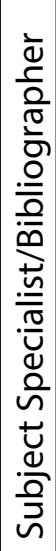 & 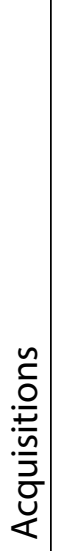 & 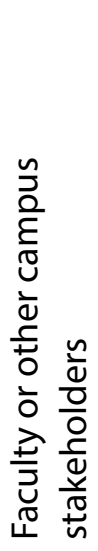 & $\frac{\bar{d}}{\frac{1}{\Delta}}$ \\
\hline $\begin{array}{l}\frac{c}{0} \\
\frac{0}{y} \\
\frac{\partial}{\partial} \\
0\end{array}$ & & & & & & & 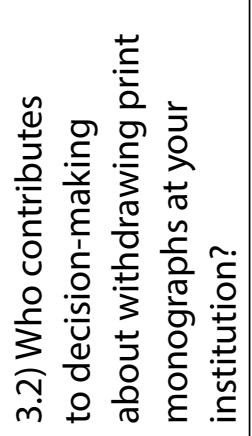 & & & & & & \\
\hline 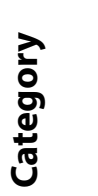 & 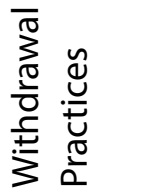 & & & & & & & & & & & & \\
\hline
\end{tabular}




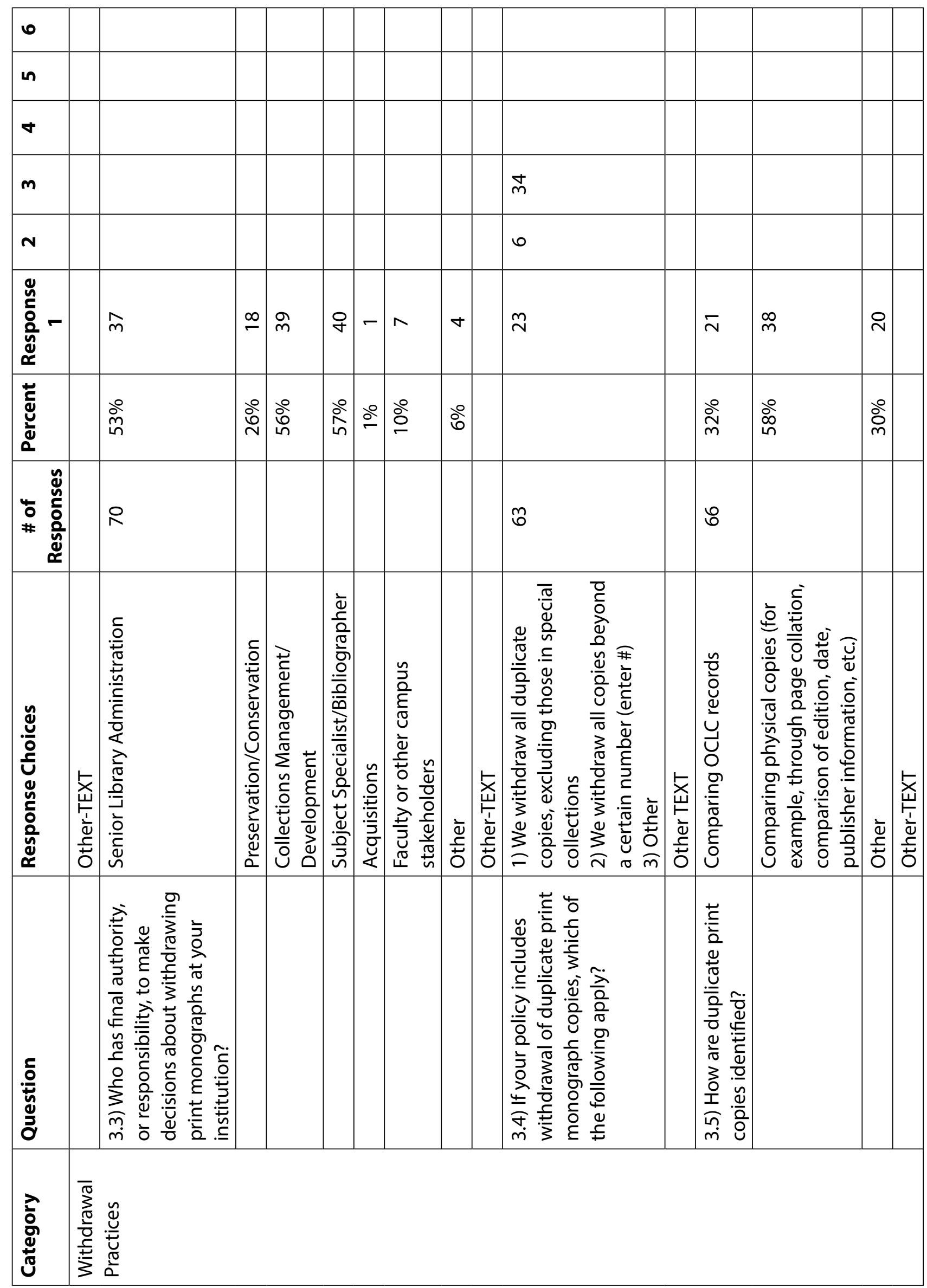




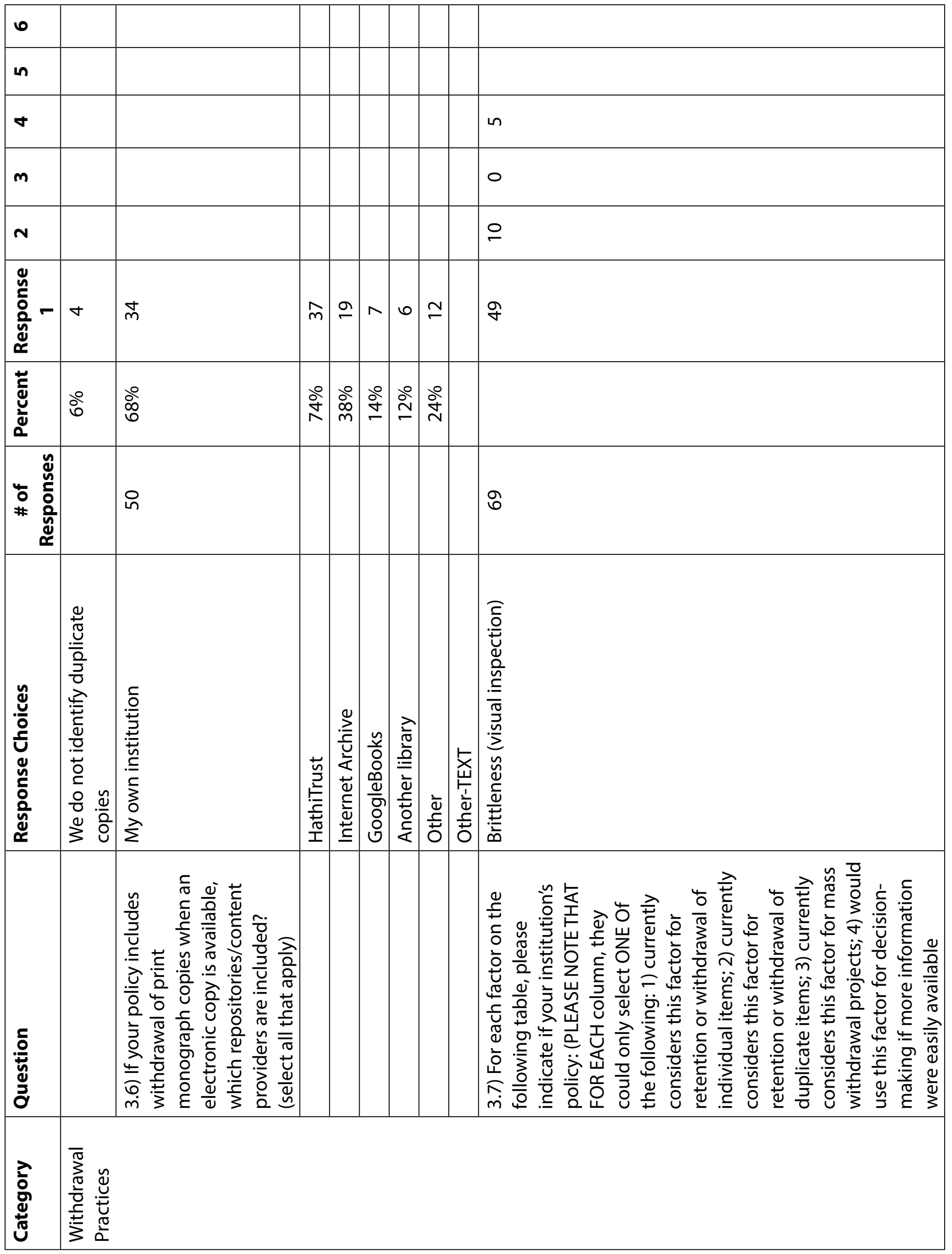




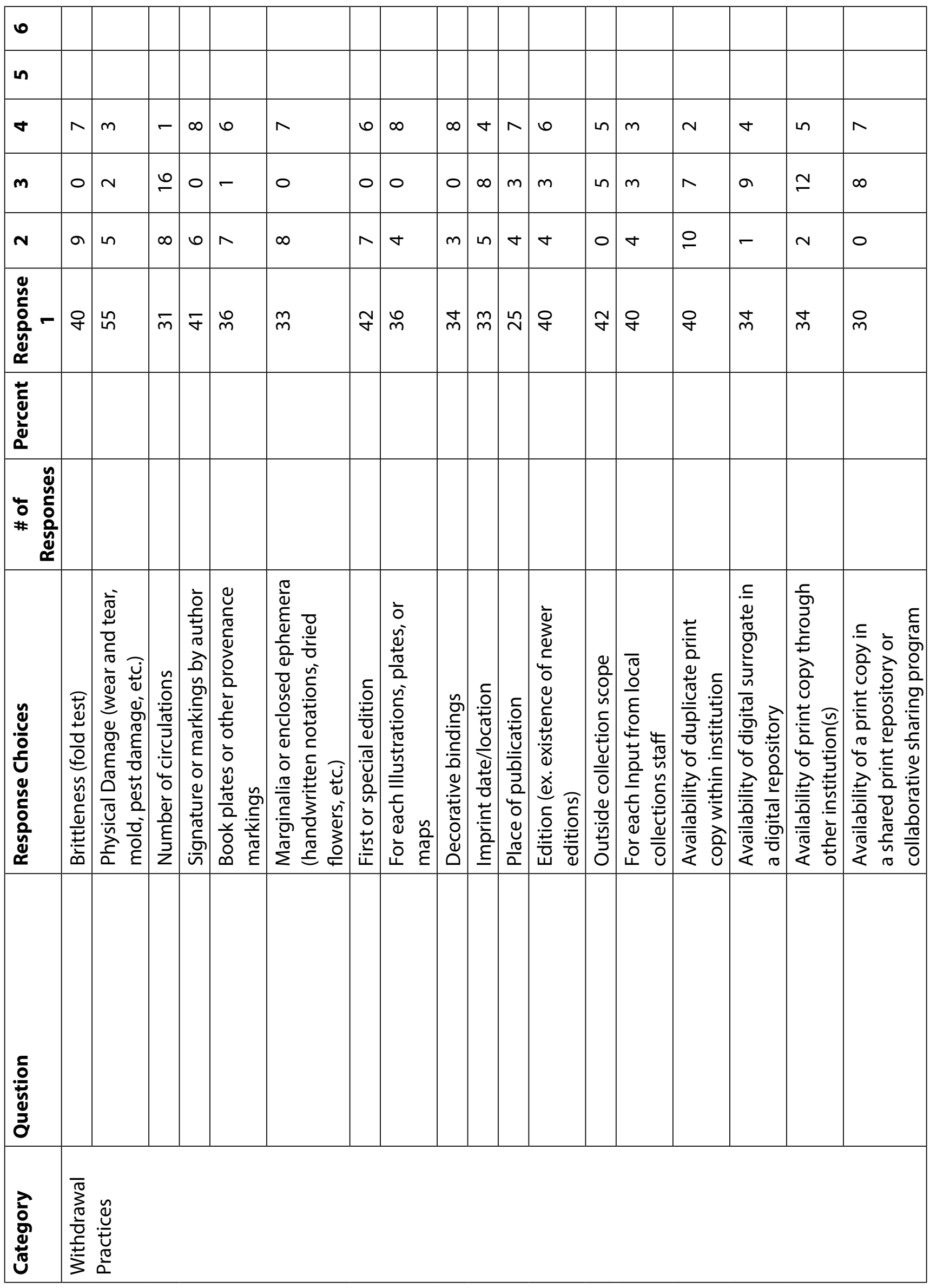




\begin{tabular}{|c|c|c|c|c|c|c|c|c|c|c|c|c|c|c|c|}
\hline$\bullet$ & & & & & & & & & & & & & & & 0 \\
\hline in & & & & & & & & & & & & & & & 0 \\
\hline$\nabla$ & $\nabla$ & $m$ & $\lambda$ & 0 & & 0 & & 0 & & & & & & & $\mp$ \\
\hline$m$ & $\infty$ & \pm & $\stackrel{m}{\square}$ & $\ln$ & & - & & 0 & & & & & & & $\stackrel{\mathscr{n}}{\sim}$ \\
\hline$N$ & $N$ & $\nabla$ & - & $\sim$ & & 0 & & 0 & & & & & & & $\stackrel{\circ}{-}$ \\
\hline 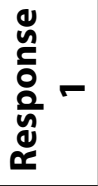 & $\stackrel{\bullet}{N}$ & $\stackrel{m}{m}$ & $\stackrel{\sim}{ }$ & 0 & & $N$ & & - & & $\stackrel{m}{\sim}$ & กี & $\stackrel{\operatorname{Ln}}{-}$ & $\infty$ & & ㄷ \\
\hline 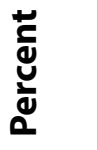 & & & & & & & & & & ஓे & ஓे & i̊̀ & $\begin{array}{l}\stackrel{\circ}{ \pm} \\
\pm\end{array}$ & & \\
\hline 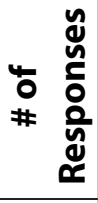 & & & & & & & & & & 冓 & & & & & ชิ \\
\hline 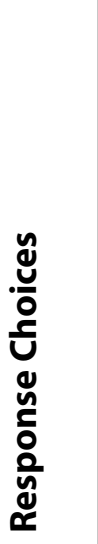 & 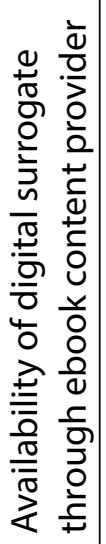 & 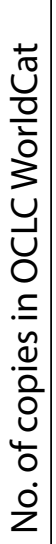 & 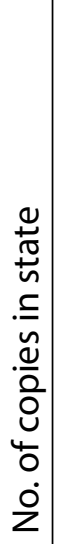 & 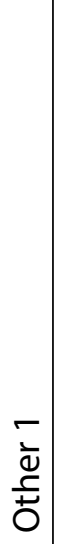 & 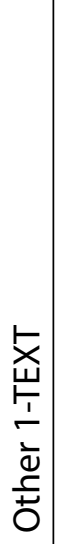 & $\begin{array}{l}\frac{N}{\nu} \\
\bar{\Xi} \\
\stackrel{ \pm}{+} \\
0\end{array}$ & 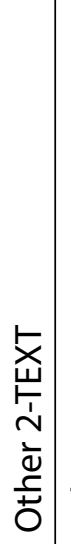 & $\begin{array}{c}m \\
\bar{d} \\
\stackrel{c}{+} \\
0\end{array}$ & 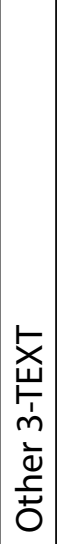 & 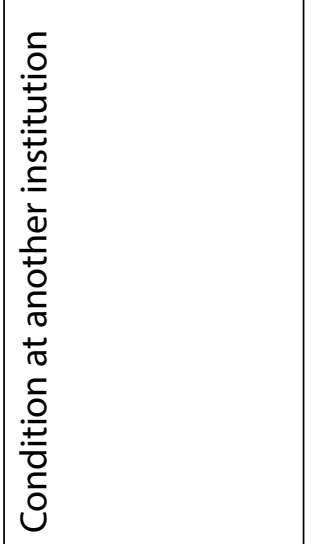 & 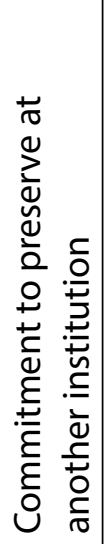 & 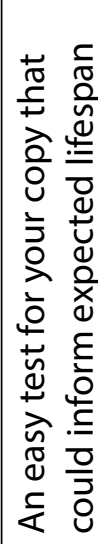 & 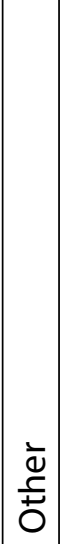 & 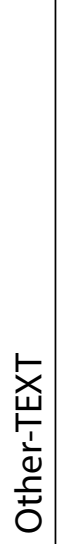 & 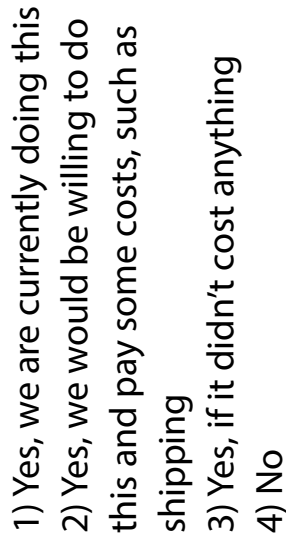 \\
\hline $\begin{array}{l}\frac{c}{0} \\
\frac{0}{y} \\
\frac{\partial}{\partial} \\
0\end{array}$ & & & & & & & & & & 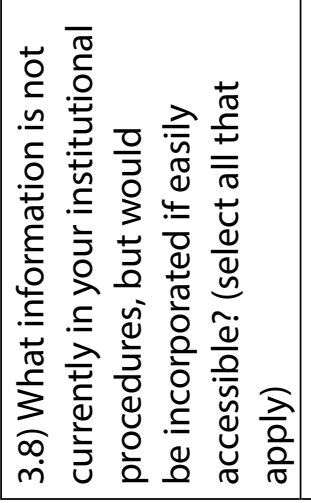 & & & & & 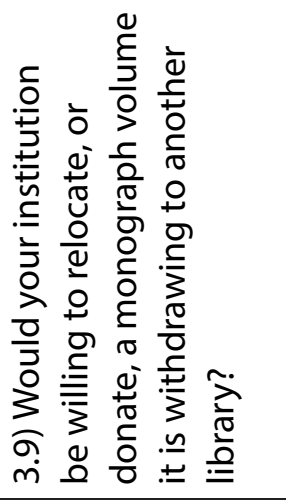 \\
\hline 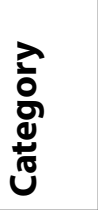 & 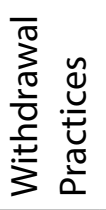 & & & & & & & & & & & & & & \\
\hline
\end{tabular}




\begin{tabular}{|c|c|c|c|c|}
\hline 0 & 0 & & & \\
\hline in & 0 & & & \\
\hline $\boldsymbol{\sigma}$ & 0 & & & \\
\hline$m$ & 0 & & & \\
\hline $\mathbf{N}$ & Ln & & 으 & \\
\hline 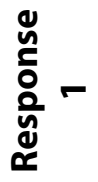 & $\stackrel{m}{n}$ & & 이 & \\
\hline 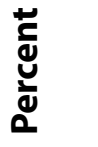 & & & & \\
\hline 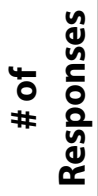 & $\mathscr{0}$ & & $\stackrel{\circ}{N}$ & \\
\hline 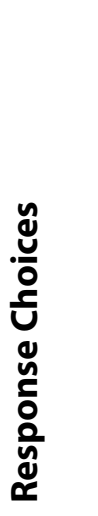 & 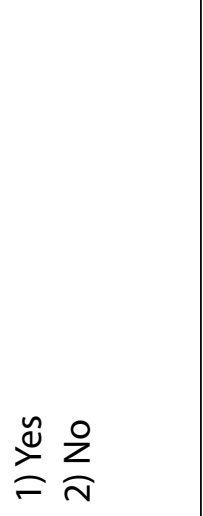 & & 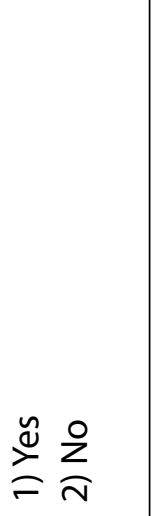 & 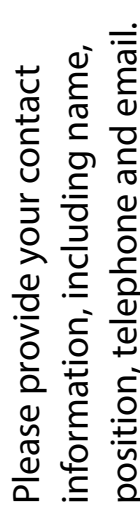 \\
\hline 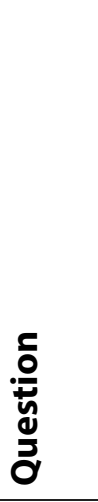 & 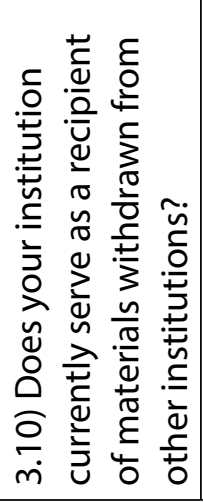 & 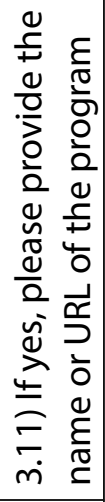 & 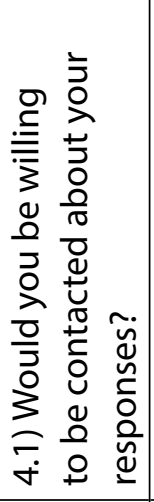 & \\
\hline 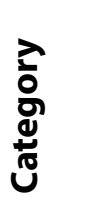 & 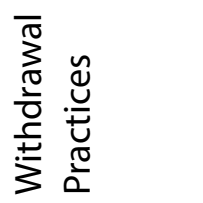 & & 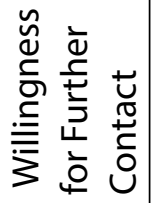 & \\
\hline
\end{tabular}




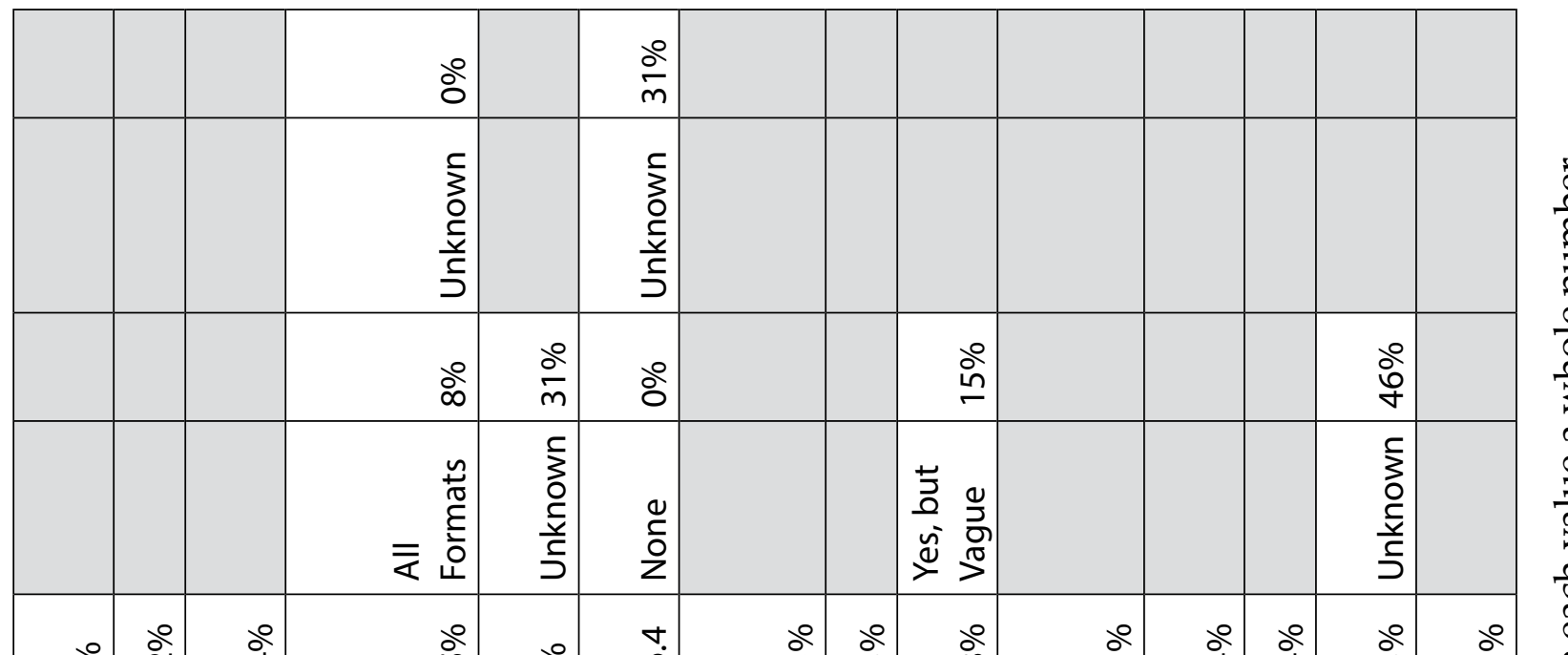

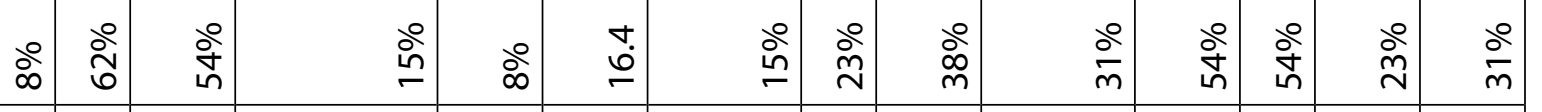

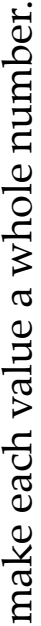

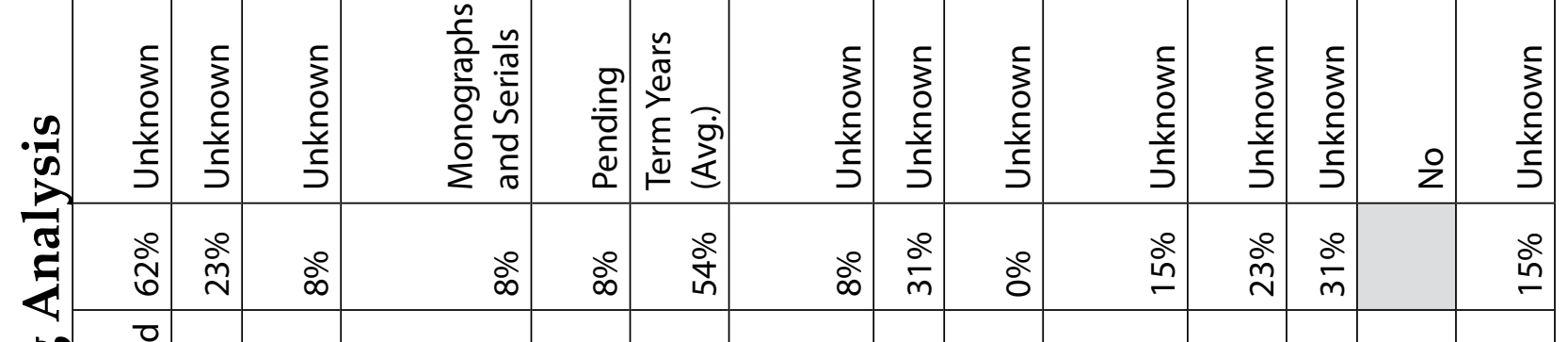

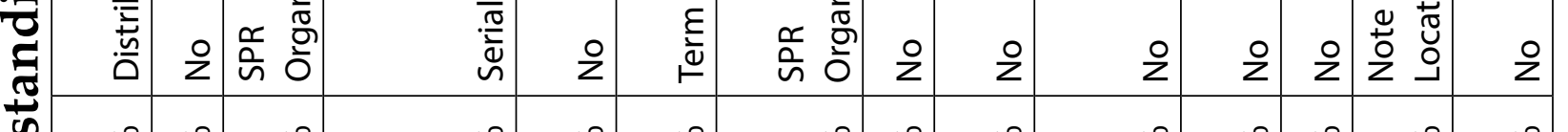

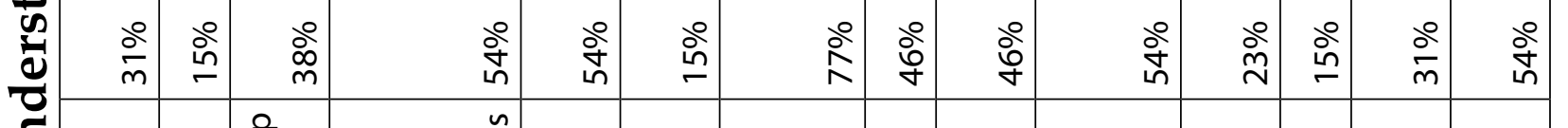

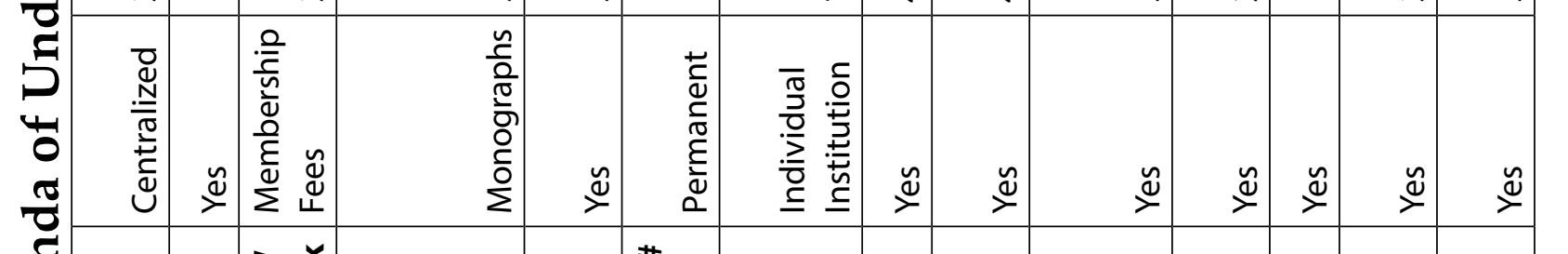

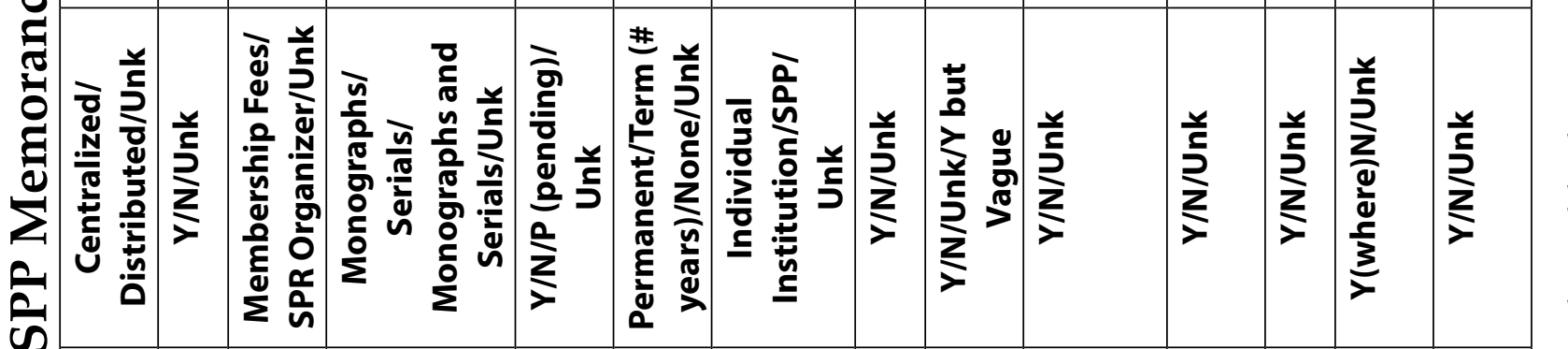

\begin{tabular}{|c|c|c|c|c|c|c|c|c|c|c|c|c|c|}
\hline & & & & & & & & & & & & & \\
\hline 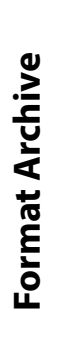 & 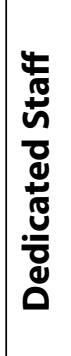 & 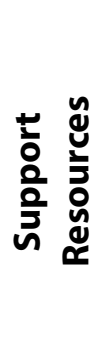 & 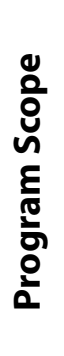 & 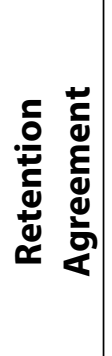 & 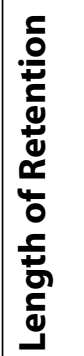 & 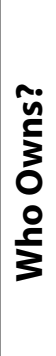 & 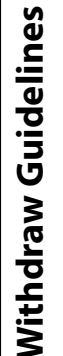 & 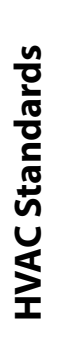 & 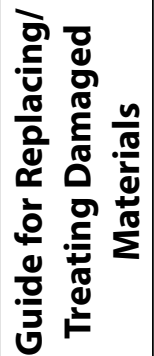 & 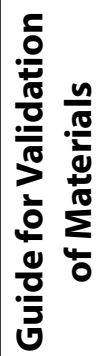 & 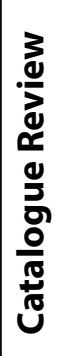 & 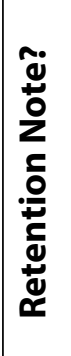 & 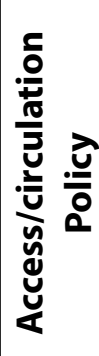 \\
\hline
\end{tabular}




\section{Notes}

1. Rick Lugg, “The Remarkable Acceleration of Shared Print," Next (Mar. 1, 2018), available online at www. oclc.org/blog/main/the-remarkable-acceleration-of-shared-print/ [accessed 10 September 2018].

2. Lugg, "The Remarkable Acceleration of Shared Print."

3. Dan Cohen et al., "Concerted Thought, Collaborative Action, and the Future of the Print Record," Modern Language Association (2016), available online at https://printrecord.mla.hcommons.org/ [accessed 24 March 2017].

4. JSTOR, “Terms and Conditions,” available online at https://about.jstor.org/terms/ [accessed 6 May 2018]; Brewster Kahle, "Why Preserve Books? The New Physical Archive of the Internet Archive." Internet Archive Blogs (2011), available online at http://blog.archive.org/2011/06/06/why-preserve-books-the-new-physical-archive-ofthe-internet-archive/ [accessed 6 May 2018].

5. Marisa Bluestone, "Book Publishing Annual StatShot Survey Reveals Religious Crossover and Inspirational Books Supported Trade Book Growth in 2016," American Association of Publishers Newsroom, available online at http://newsroom.publishers.org/book-publishing-annual-statshot-survey-reveals-religious-crossoverand-inspirational-books-supported-trade-book-growth-in-2016 [accessed 30 March 2018].

6. Andrew Stauffer, "My Old Sweethearts: On Digitization and the Future of the Print Record," in Debates in the Digital Humanities, eds. Matthew K. Gold and Lauren F. Klein (Minneapolis, MN: University of Minnesota Press, 2016), 218-29, available online at http://dhdebates.gc.cuny.edu/debates/text/70 [accessed 24 March 2017].

7. Kristen Jensen et al., “Book Traces @ UVA,” Council on Library and Information Resources, University of Virginia (2017), available online at https://libraopen.lib.virginia.edu/public_view/cv43nw88q [accessed 26 October 2017].

8. Jensen et al., "Book Traces @ UVA."

9. Maryanne Wolf, Proust and the Squid: The Story and Science of the Reading Brain (New York, NY: Harper, 2007).

10. Wolf, Proust and the Squid.

11. Gemma Walsh, "Screen and Paper Reading Research: A Literature Review," Australian Academic \& Research Libraries 47, no. 3 (2016): 160-73, available online at https://doi.org/10.1080/00048623.2016.1227661.

12. Walsh, "Screen and Paper Reading Research: A Literature Review."

13. Walsh, "Screen and Paper Reading Research: A Literature Review."

14. Walsh, "Screen and Paper Reading Research: A Literature Review."

15. Walsh, "Screen and Paper Reading Research: A Literature Review."

16. Robert H. Kieft and Lizanne Payne, "A Nation-Wide Planning Framework for Large-Scale Collaboration on Legacy Print Monograph Collections," Collaborative Librarianship 2, no. 4 (2010): 229-33.

17. Center for Research Libraries, "Print Archiving and Shared Print in North America: A Preliminary Analysis and Status Report," Preserving America's Print Resources II: A North American Summit (Sept. 10, 2015), available online at www.crl.edu/sites/default/files/attachments/events/PAPR_summit_preliminary_analysis2_revised.pdf [accessed 24 March 2017].

18. Cohen et al., "Concerted Thought, Collaborative Action, and the Future of the Print Record."

19. Lorcan Dempsey et al., Understanding the Collective Collection: Towards a System-wide Perspective on Library Print Collections (Dublin, OH: OCLC Research, 2013), available online at https://www.oclc.org/content/dam/ research/publications/library/2013/2013-09.pdf [accessed 12 September 2018].

20. Dempsey et al., Understanding the Collective Collection.

21. Candace Arai Yano, Zuo-Jun Max Shen, and Stephen Chan, "Optimising the Number of Copies and Storage Protocols for Print Preservation of Research Journals," International Journal of Production Research 51, no. 23/24 (2013): 7456-69.

22. Yano, Shen, and Chan, "Optimising the Number of Copies and Storage Protocols for Print Preservation of Research Journals."

23. Roger C. Schonfeld and Ross Housewright, "What to Withdraw? Print Collections Management in the Wake of Digitization," Ithaka S+R (2009), available online at https://doi.org/10.18665/sr.22357; Jacob Nadal and Annie Peterson, "Scarce and Endangered Works: Using Network-level Holdings Data in Preservation Decisionmaking and Stewardship of the Printed Record" (2014), available online at www.jacobnadal.com/wp-content/ uploads/2011/05/ScarceAndEndangeredWorksv7.pdf [accessed 23 March 2017].

24. Paul Conway, "Preserving Imperfection: Assessing the Incidence of Digital Imaging Error in HathiTrust," Digital Technology and Culture 42, no. 1 (2013): 17-30, available online at https://doi.org/10.1515/pdtc-2013-0003.

25. Conway, "Preserving Imperfection." 
26. Randy Silverman, "Surely We'll Need Backups," Preservation, Digital Technology \& Culture 43, no. 3 (2016): $102-21$.

27. Brian Lavoie, Constance Malpas, and J.D. Shipengrover, Print Management at "Mega-scale": A Regional Perspective on Print Book Collections in North America (Dublin, OH: OCLC Research, 2012), available online at https:// www.oclc.org/content/dam/research/publications/library/2012/2012-05.pdf [accessed 30 November 2018].

28. Wyoma van Duinkerken, "Lessons Learned: Can a Resource in Common Work?" New Library World 113, no. 1/2 (2012): 65-76, available online at https://doi.org/10.1108/03074801211199059.

29. Esther E. Carrigan, Nancy C. Burford, and Ana G. Ugaz, "One Library's Story: Building a Texas-Sized Shared Print Repository," in Health Sciences Collection Management for the Twenty-First Century, ed. Susan K. Kendall (Lanham, MD: Rowman \& Littlefield, 2018), 167-72.

30. Carrigan, Burford, and Ugaz, "One Library's Story."

31. Center for Research Libraries, "Print Archives Preservation Registry," available online at http://papr.crl. edu/ [accessed 19 November 2018]

32. Rebecca Crist and Emily Stambaugh, SPEC Kit 345: Shared Print Programs (Washington, DC: Association of Research Libraries, 2014), available online at https://doi.org/10.29242/spec.345.

33. David F. Kohl, Circulation, Interlibrary Loan, Patron Use, and Collection Management: A Handbook for Library Management (Santa Barbara, CA: ABC-CLIO, 1986).

34. Nadal and Peterson, "Scarce and Endangered Works."

35. Vicky Reich and David S.H. Rosenthal, "LOCKSS: A Permanent Web Publishing and Access System," D-Lib Magazine 7, no. 6 (2001), available online at https://doi.org/10.1045/june2001-reich. 